\title{
BMJ Open Protocol to assess the impact of tobacco- induced volatile organic compounds on cardiovascular risk in a cross- sectional cohort: Cardiovascular Injury due to Tobacco Use study
}

Rachel J Keith, ${ }^{1,2}$ Jessica L Fetterman, ${ }^{3,4}$ Daniel W Riggs, ${ }^{1,2}$ Timothy O'Toole, ${ }^{1,2}$ Jessica L Nystoriak, ${ }^{1,2}$ Monika Holbrook, ${ }^{3,4}$ Pawel Lorkiewicz, ${ }^{1,2}$ Aruni Bhatnagar, ${ }^{1,2}$ Andrew P DeFilippis, ${ }^{1,2}$ Naomi M Hamburg ${ }^{3,4}$

To cite: Keith RJ, Fetterman JL, Riggs DW, et al. Protocol to assess the impact of tobaccoinduced volatile organic compounds on cardiovascular risk in a cross- sectional cohort: Cardiovascular Injury due to Tobacco Use study. BMJ Open 2018;8:e019850. doi:10.1136/ bmjopen-2017-019850

- Prepublication history for this paper is available online. To view these files, please visit the journal online (http://dx.doi. org/10.1136/bmjopen-2017019850).

Received 5 October 2017 Revised 14 February 2018 Accepted 19 February 2018

Check for updates

${ }^{1}$ Division of Cardiovascular Medicine, University of Louisville School of Medicine, Louisville, Kentucky, USA

${ }^{2}$ American Heart Association Tobacco Regulation and Addiction Center, University of Louisville

${ }^{3}$ Vascular Biology Section, Whitaker Cardiovascular Institute, Boston University School of Medicine, Boston, Massachusetts, USA

${ }^{4}$ American Heart Association

Tobacco Regulation and

Addiction Center, Boston University

Correspondence to Dr Rachel J Keith; rachel.keith@louisville.edu

\section{ABSTRACT}

Introduction Tobacco use leads to increased mortality, the majority of which is attributed to cardiovascular disease. Despite this knowledge, the early cardiovascular impact of tobacco product use is not well understood. Tobacco use increases exposure to harmful and potentially harmful constituents including volatile organic compounds (VOCs) such as acrolein and crotonaldehyde, which may contribute to cardiovascular risk. The link between exposure patterns, risk profiles and demographic distribution of tobacco product users, particularly users of new and emerging products, are not well known. Therefore, we designed the Cardiovascular Injury due to Tobacco Use (CITU) study to assess population characteristics, demographic features, exposure patterns and cardiovascular risk in relation to tobacco

Methods and analysis We present the design and methodology of the CITU study, a cross-sectional observational tobacco study conducted in Boston, Massachusetts and Louisville, Kentucky starting in 2014. Healthy participants $21-45$ years of age who use tobacco products, including electronic nicotine devices, or who never used tobacco are being recruited. The study aims to recruit an evenly split cohort of African-Americans and Caucasians, that is, sex balanced for evaluation of selfreported tobacco exposure, VOC exposure and tobaccoinduced injury profiling. Detailed information about participant's demographics, health status and lifestyle is also collected.

Ethics and dissemination The study protocol was approved institutional review boards at both participating universities. All study protocols will protect participant confidentiality. Results from the study will be disseminated via peer-reviewed journals and presented at scientific conferences.

\section{INTRODUCTION}

Tobacco product use and smoking are the leading causes of preventable deaths throughout the world. Of those deaths,

\section{Strengths and limitations of this study}

- Young age to allow for evaluation of early-stage disease (eg, inflammation, endothelial function) as opposed to end-stage clinical consequence (eg, myocardial infarction).

- Diverse tobacco product use allows for assessment of a wide range of tobacco-induced volatile organic compound exposure.

- All study visits are in English introducing selection bias.

- Data will inform regulatory agencies on the cardiovascular health effects of multiple tobacco products and the contribution of harmful and potentially harmful constituents.

one-third are attributed to cardiovascular disease (CVD). ${ }^{1}$ The cardiovascular (CV) effects of tobacco exposure can include atherogenesis, vascular injury, thrombosis, arrhythmias and inflammation ${ }^{2}$ and may be attributable to the many different harmful and potentially harmful constituents (HPHCs) present in tobacco products.

The HPHCs found in tobacco products include volatile organic compounds (VOCs) of which reactive aldehydes, such as acrolein and crotonaldehyde, are likely the most significant contributors to $\mathrm{CV}$ toxicity. ${ }^{3} \mathrm{High}$ levels of aldehydes are present in cigarette smoke $^{45}$ as well as smokeless tobacco. ${ }^{6}$ Risk assessments, using the prevalence of each individual chemical weighed by its potency, suggest that the non-cancer risk of smoking is dominated by acrolein, which contributes 40-100 times more to risk than any other chemicals present in cigarette smoke. ${ }^{3}$

Although HPHCs, including VOC reactive aldehydes, have been suspected to be major 
contributors to the toxicity of cigarette smoke for over four decades, their contribution to CV injury and early-CVD risk has not been rigorously evaluated. Experimental studies in animal models suggest that because of low aldehyde-metabolising capacity, CV tissues are highly sensitive to aldehydes and exposure to low levels of aldehydes can induce CV injury and accelerate CVD. ${ }^{7-18}$ WHO Study Group on Tobacco Product Regulation has marked acrolein, a VOC, along with eight other cigarette constituents for monitoring and regulation ${ }^{19}$ and the US Environmental Protection Agency (EPA) lists Acrolein as one of most hazardous air pollutants. ${ }^{20}$ Nevertheless, the contribution of tobacco-induced VOCs, including acrolein or other aldehydes, towards CV toxicity in humans has not been fully assessed. Greater understanding of how aldehydes affect CV health and disease will provide new avenues for evaluating the toxicity of cigarette smoke and for assessing the injurious potential of new and emerging tobacco products, such as electronic nicotine devices (ENDs), which may also contain VOCs including acrolein. ${ }^{21-23}$

The latency period between tobacco exposure and the development of major clinical adverse health effects is long, therefore, biomarkers that provide information over a shorter period allow for the identification of harm decades before clinical outcome data is available. Thus, in this paper, we present the design and methodology of the Cardiovascular Injury due to Tobacco Use (CITU) study which will evaluate the association of the urinary metabolites of 18 parent VOCs from tobacco exposure with a comprehensive set of CV biomarkers representative of early disease and predictive of future CV events. ${ }^{24}$

\section{METHODS AND DESIGN \\ Overall design}

The CITU study is an investigator-initiated cross-sectional observational study of around 500 healthy participants 21-45 years of age who are never or current tobacco product users in two urban areas at Boston University (BU) and University of Louisville (UofL) (Boston, Massachusetts and Louisville, Kentucky) designed to evaluate $\mathrm{CV}$ toxicity due to tobacco product use, with correlations to VOCs found in the tobacco products (figure 1).

\section{Participant eligibility criteria}

The goal of the study is to examine the impact of tobacco products on healthy young adults who could be classified as a current tobacco product users (defined in table 1) or never-users (does not have lifetime use of any tobacco product). Participants were self-reported to be healthy, therefore, we excluded participants if they had: (1) diagnosis of clinical CVD including but not limited to known heart attack, peripheral artery disease, heart failure or stroke; (2) diagnosis of diabetes (haemoglobin A1c $>7.0$ or treatment for diabetes), hypertension (systolic blood

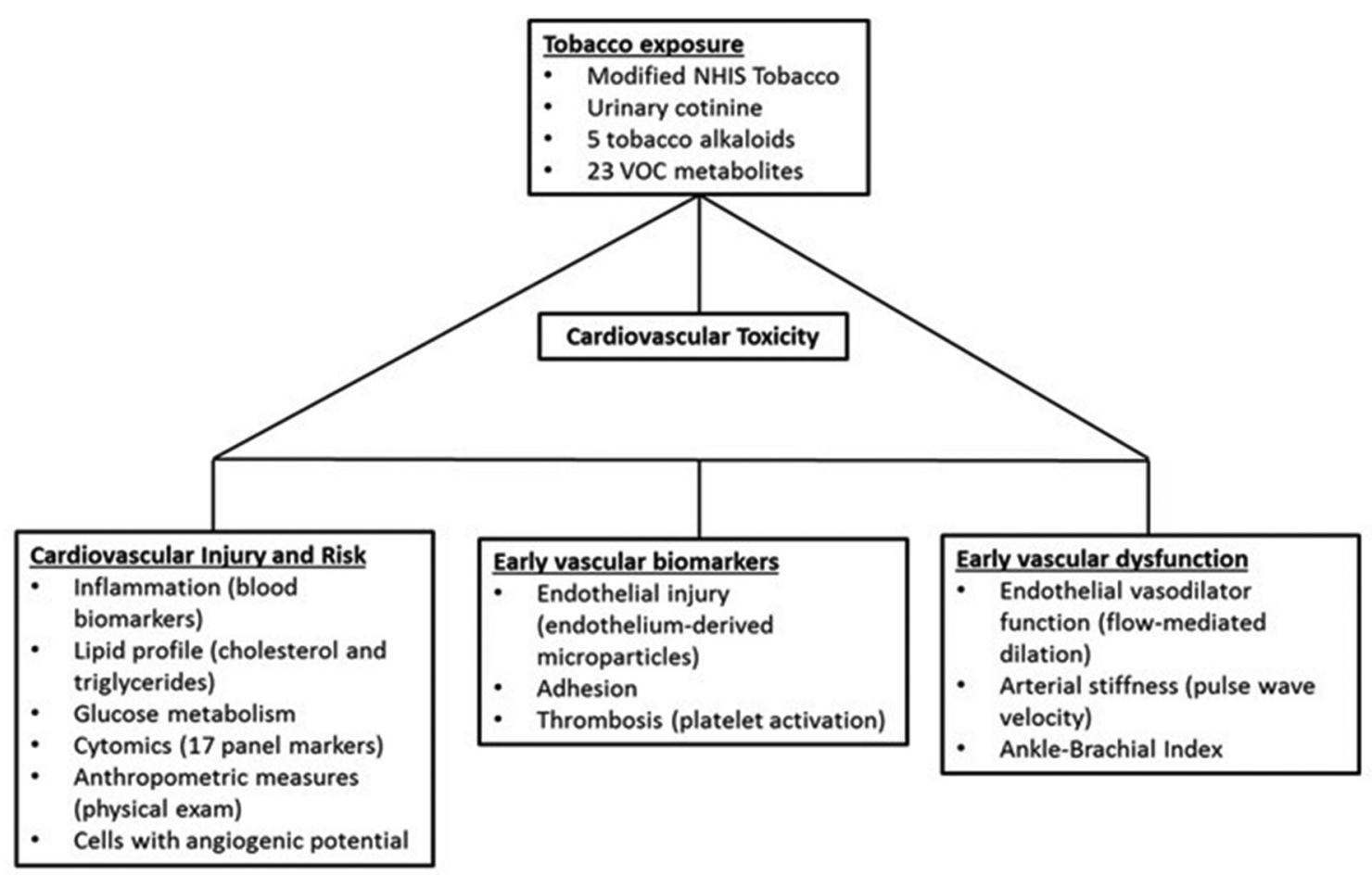

Figure 1 Cardiovascular Injury due to Tobacco Use (CITU). CITU is designed to assess how tobacco-related volatile organic compound (VOC) exposure contributes to cardiovascular risk factors. Our exposure measurements include a panel of 23 urinary metabolites of 18 parent VOCs and tobacco use patterns. Cardiovascular phenotyping includes measures of injury, risk, vascular biomarkers and early-vascular dysfunction. Tobacco use included use of traditional cigarettes, smokeless tobacco, waterpipe tobacco (hookah), electronic nicotine devices, little cigars, cigarillos, pipes, cigars or any other form of tobacco that is available. Enrolment began in July 2014 and is ongoing. NHIS, National Health Interview Survey. 


\begin{tabular}{|c|c|}
\hline Classification & Qualification \\
\hline Never & $\begin{array}{l}\text { Does not meet lifetime limits for any } \\
\text { tobacco use (see below) }\end{array}$ \\
\hline Smoker & $\begin{array}{l}>100 \text { lifetime cigarettes and current } \\
\text { use for the past year }\end{array}$ \\
\hline $\begin{array}{l}\text { Smokeless } \\
\text { tobacco user }\end{array}$ & $\begin{array}{l}>20 \text { lifetime dips or chews and current } \\
\text { use for the past year }\end{array}$ \\
\hline Cigar/cigarillo user & $\begin{array}{l}>20 \text { lifetime cigars or cigarillos and } \\
\text { current use for the past year }\end{array}$ \\
\hline Pipe user & $\begin{array}{l}>20 \text { lifetime pipefuls and current use } \\
\text { for the past year }\end{array}$ \\
\hline ENDs user & $\begin{array}{l}>20 \text { lifetime vape sessions and current } \\
\text { use for the past year }\end{array}$ \\
\hline Hookah user & $\begin{array}{l}>20 \text { lifetime hookah sessions and } \\
\text { current use for the past year }\end{array}$ \\
\hline
\end{tabular}

Study participants are screened prior to enrolment for current and past tobacco product use. Participants are characterised and assigned a use group based on self-reported patterns collected during the study visits.

ENDs, electronic nicotine devices.

pressure $>140 \mathrm{~mm} \mathrm{Hg}$ or diastolic blood pressure $>90 \mathrm{~mm}$ $\mathrm{Hg}$ ), hypothyroidism or hyperthyroidism, inflammatory conditions such as lupus or inflammatory bowel disease, HIV/AIDS, hepatitis, liver disease, anaemia, cancer of any type or another medical condition that might compromise the successful completion of the study; (2) recipients of organ transplant or renal replacement therapy; (3) individuals who are taking the following medications: immunosuppressant agents oestrogen, testosterone, anti-TNF agents, certain biologicals, Procrit, statins, beta-blockers or other CV medicine; (4) individuals using nutraceuticals or anabolic steroids beyond the recommended daily allowance; (5) body weight less than 100 pounds; (6) pregnant women; (7) prisoners and other vulnerable populations and (8) active illness or infection. Participants are rescheduled or considered screen failures and excluded from the study if symptomatic of an acute illness, that is, viral upper respiratory infection, on study date.

\section{Overall study procedure}

Study participants fast for 8 hours from food and 6 hours from tobacco prior to the visit. All study visits occur before 11:00 hours to limit effects due to circadian changes. All vascular function studies are completed after $10 \mathrm{~min}$ of supine positioning. All vascular studies are sent to the BU central laboratory for analysis. BU biological samples have minimal processing and are shipped overnight to the UofL central laboratory at the completion of each study visit. Samples obtained at UofL are processed to a similar stage, then held overnight prior to analysis for standardisation of time to measurement for all samples.

Study visits take approximately $90 \mathrm{~min}$ to complete and include a structured interview on demographics, socioeconomics, lifestyle, health, family history of heart disease, allergies and tobacco use (figure 2). Participants were compensated appropriately for their time. All surveys are collected and kept in Research Electronic Data Capture, a secure web application for building and managing online surveys and databases.

\section{Exposure variables}

Tobacco product use and particulate matter exposure

Comprehensive tobacco product exposure is assessed using a modified version of the National Health Interview survey on tobacco use. ${ }^{25}$ The survey is modified to include detailed information on ENDs and other new or emerging tobacco products. Residential addresses are collected for assessment of ambient airborne particulate matter $\left(\mathrm{PM}_{2.5}\right)$ exposure and future correction of overall exposure. $\mathrm{PM}_{2.5}$ data from the day of the study visit, and 3 and 5 days prior to the study is collected from publicly available data associated with EPA monitoring stations. Other exposure variables, including occupation, are collected through interview.

\section{VOC measurements}

Humans are exposed to VOCs from a variety of sources including indoor and outdoor environments as well as diet. The most significant sources of ambient exposure ambient are air pollution, car exhaust, household products, personal hygiene products and solvents. ${ }^{26} 27$ Although concurrent exposures from multiple sources could confound attribution to smoking, the levels of urinary metabolites of these VOCs in smokers far exceeds those measured in non-smokers exposed to typical sources of VOCs. ${ }^{28}$

Standard clean catch urine specimens are obtained from participants. Though only a single urine time

\section{Day of study visit}

\begin{tabular}{|c|c|c|c|c|c|}
\hline $\begin{array}{l}\text { Pre-consent } \\
\text { eligibility screen }\end{array}$ & $\begin{array}{l}\text { Tobacco and } \\
\text { food fast }\end{array}$ & $\begin{array}{l}\text { Consent and re- } \\
\text { screen }\end{array}$ & $\begin{array}{l}\text { Detailed Surveys } \\
\text { collected }\end{array}$ & $\begin{array}{c}\text { Vascular Testing } \\
\text { and }\end{array}$ & $\begin{array}{c}\text { Biospecimen } \\
\text { collection }\end{array}$ \\
\hline $\mathrm{T}=-1$ or 2 weeks & $\begin{array}{c}T=-8 \mathrm{~h} \text { food } \\
T=-6 \mathrm{~h} \text { tobacco }\end{array}$ & $\mathrm{T}=15 \mathrm{~min}$ & $\mathrm{~T}=30 \mathrm{~min}$ & \begin{tabular}{|c} 
anthropometric \\
measures
\end{tabular} & $\mathrm{T}=15 \mathrm{~min}$ \\
\hline
\end{tabular}

Figure 2 Study visit design. Study flow chart for interested participants from screening through study completion. Potential participants are prescreened for eligibility prior to enrolment. Potential participants are asked to fast from tobacco for a minimum of 6 hours prior to the study visit. On the day of the visit, the study lasts approximately 90 min. 
point is collected, previous studies show spot urine measurements correlate well with 24-hour urine collections. ${ }^{29}$ Many VOC metabolites have relatively short halflives that range from 2 to 25.2 hours, ${ }^{30}{ }^{31}$ but given the constant pattern of tobacco product use by most users, spot collection reflects recurrent use. Moreover, even though some VOC metabolites, such as N-Acetyl-S-(3-hydroxypropyl)cysteine (HPMA), are known vary with time of day, ${ }^{29}$ synchronising the study visits and requiring a tobacco fast is likely to minimise diurnal variations in metabolism. Our past work has shown that spot urine collected at the same time of day reliably reflects daily VOC exposure and is correlated to CVD risk. ${ }^{32}$

We have developed a robust Core Laboratory that uses mass spectrometry procedures adopted from the Centers for Disease Control and Prevention protocols, to quantify 23 urinary metabolites of tobacco smoking-related toxins (aldehydes and other VOCs), including acrolein ${ }^{33}$ (table 2). The concentration values of analytes are then normalised to urinary creatinine levels measured using Infinity Creatinine Reagent (Thermo Fisher Scientific, Massachusetts) on a COBAS MIRA-plus analyser (Roche, New Jersey).

\section{Circulating markers of CV injury}

To assess tobacco product-induced CV toxicity, we examine endothelial function, inflammatory mediators, biomarkers and thrombosis. CV risk is defined through measurements of circulating angiogenic cells, lipid profile and glucose metabolism. ${ }^{24} 34{ }^{35}$ Plasma (BD367863 and BD366415) and serum (BD367814) samples are obtained from all participants for laboratory testing and longterm biobanking. Whole blood (BD366415) is obtained for flow cytometry on fresh samples at UofL pathology core. BU biological samples have minimal processing and are shipped overnight to the UofL central laboratory at the completion of each study visit. Samples obtained at UofL are processed to a similar stage, then held overnight prior to analysis to standardise the time to measurement for all samples. The UofL central laboratory, as previously reported, will complete fasting and biomarker measurements (box 1), with the exception of cytomics. ${ }^{12}{ }^{36}$ For cytomic measurements, mononuclear cells are labelled with the peripheral blood phenotyping panel kit (Fluidigm). Samples are shipped at $4^{\circ} \mathrm{C}$ to Core Laboratory facilities at the University of Rochester for Mass cytometric analysis.

\section{Non-invasive vascular function testing}

Smoking is associated with endothelial damage and vascular dysfunction. ${ }^{37} 38$ Endothelial cells are exposed to circulating toxins and measures of endothelial function are reflective of CV injury. ${ }^{39}$ Thus, we examine the non-invasive endothelial vasodilator function using flow-mediated vasodilation (FMD), ${ }^{40}{ }^{41}$ arterial stiffness with carotid-femoral and carotid-radial pulse wave velocity, ${ }^{42}$ and peripheral vascular function with ankle brachial index. Flow-mediated dilation was assessed with a 7.5 MHz ultrasound probe is used to image the brachial artery while a $10 \mathrm{~cm}$ blood pressure cuff is attached to the lower arm and a 3-lead ECG is attached to the patient. After baseline images and 10 cycles of Doppler images are captured using NIHEM R-wave triggered image capturing software, the blood pressure cuff is inflated to $200 \mathrm{~mm} \mathrm{Hg}$ or $50 \mathrm{~mm} \mathrm{Hg}$ higher than the systolic pressure. After the 5 min occlusion, the cuff is released and the NIHEM software records $2 \mathrm{~min}$ of imaging. Images were analysed by a single-blinded analyser using Medical Imaging Applications (MIA) vascular Research Tools Brachial Analyzer for Research, V.6.8.5. All vascular imagers where trained at $\mathrm{BU}$ who have a previously reported reproducibility with intraobserver and interobserver correlation coefficients of 0.98 and 0.99 for brachial diameter and 0.78 and 0.92 for FMD. ${ }^{43}$ Similar equipment and software is used at both sites. All vascular studies are sent to the BU central laboratory for analysis.

\section{Anthropometric measures}

Anthropometric measures included height, weight, waist and hip circumference, and body fat. All anthropometric measures are completed two times and the average recorded. Standing height measurements are completed on a fixed stadiometer. Weight measurements are completed on a digital scale to the nearest 10th of a pound. Waist circumference is measured at the level of the umbilicus to the nearest 10th of a centimetre. Hip circumference is measured at the maximal protrusion of the gluteal muscle to the nearest 10th of a centimetre. Body fat percentage is calculated by the bioelectrical impedance measured with the Omron fat loss monitor (HBF-306C).

\section{DATA ANALYSIS}

We expect that from this study we will be able to identify specific biomarkers of CITU and the relationship of these biomarkers to specific measures of tobacco exposure. For instance, we will identify which biomarkers are affected by tobacco use, and which ones are most sensitive, including their dose dependence. Additionally, we will examine the extent to which biomarkers are associated with exposure to nicotine versus exposure to HPHC of tobacco-like aldehydes.

\section{Sample size}

The sample size is justified in terms of the primary dependent measure, FMD, given the potential importance of this variable as a direct measure of the impact of tobacco exposure. The main comparisons are between non-tobacco users and tobacco users. Due to one control group, we will conservatively adjust our $\alpha$ (significance level) using a Bonferroni correction, and we will set $\alpha=0.01$. Based on preliminary data for FMD, we have observed mean $\pm \mathrm{SD}$ in smoker and non-smoker groups to be $4.0 \pm 1.6$ and $6.8 \pm 1.0$, respectively. We consider at least $25 \%$ (mean $\mathrm{FMD}=3.0$ from 
Table 2 Exposure variables (please see VOC measurements)

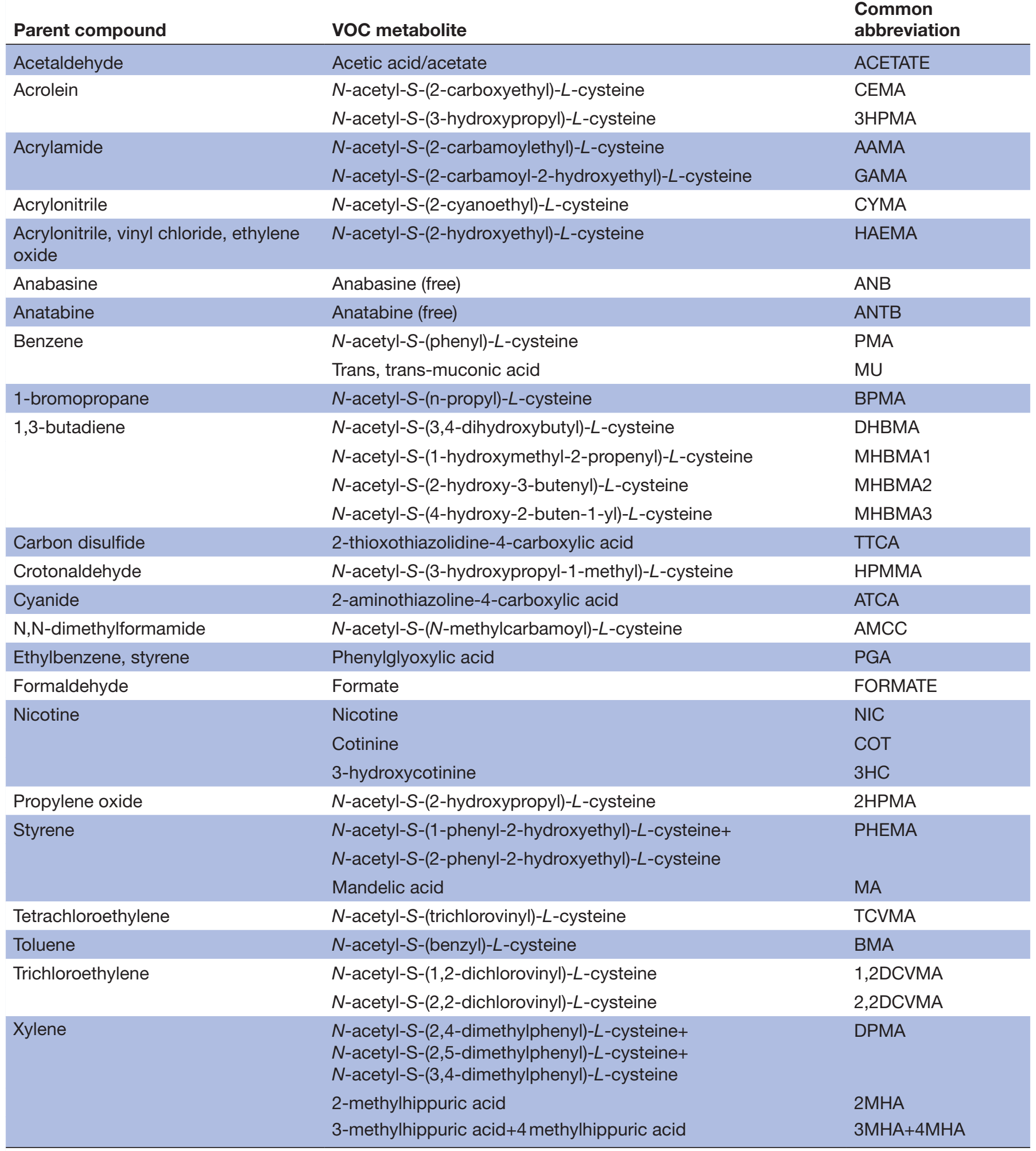

Urine is analysed for 23 metabolites of 18 parent VOCs and tobacco alkaloids by UPLC-MS/MS. Analytes are listed as parent, metabolite and their common abbreviation.

UPLC-MS, ultra performance liquid chromatography - mass spectrometer; vOC, volatile organic compound.

4.0) reduction from smokers to non-smokers is meaningful. Using a two sample, one-sided t-test with an $\alpha$ of $0.01 \%$ and $80 \%$ power (1- $\beta$ ), assuming a common $\mathrm{SD}$ of 1.3 , we will need 34 evaluable subjects in each group. We will recruit a total of 120 tobacco using participants per site. This oversampling will allow us to look at multiple endpoints and for associations with VOCs. 


\section{Box 1 Blood analysis}

\section{Fasting measurements}

LDL cholesterol, HDL cholesterol, total cholesterol, triglycerides, glucose, uric acid,

SAA and fibrinogen

\section{Biomarkers}

CAC $(1-15)^{\star}$, Platelet-monocyte aggregates, MP (1-5)*, PF4, t-PA, TxA2, Factor VII,

IL-6, CRP, D-dimer, PAI-1, s-ICAM-1, s-VCAM, s-thrombomodulin, s-TNFR1, MMP-

2, MMP-3, MMP-9, cytomics, endothelin, E-selectin and P-selectin

*Fifteen different CAP subpopulations and five subtypes of microparticles were measured by flow cytometry.

All participants who complete the study visit will have blood samples taken and processed. Flow cytometric analysis is completed on fresh samples. All other analysis will be completed on biobanked samples in batches.

CAC, circulating angiogenic cells; CRP, C reactive protein; HDL, high-density lipoprotein; IL-6, Interleukin 6; LDL, low-density lipoprotein; MMP, matrix metalloproteinase; MP, microparticles; PAl, plasminogen activator; PF4, Plateletfactor 4; SAA, serum amyloid A; s-ICAM-1, soluble intercellular adhesion molecule-1; s-VCAM, soluble vascular adhesion molecule; t-PA, tissue plasminogen activator; TxA2, thromboxane A2; TNFR1, tumour necrosis factor receptor 1.

\section{Analysis plan}

All statistical analysis will be performed using SAS V.9.4 software (SAS Institute), and a two-sided $\mathrm{p}<0.05$ will be considered significant for any statistical test. Demographics and other baseline characteristics will be summarised according to product group. Differences in VOC's between product groups will be tested using analysis of variance for normally distributed data or Kruskal-Wallis test for non-normal data. The association between primary outcomes of vascular function as well as circulating markers of $\mathrm{CV}$ injury with individual VOC levels will be analysed using multiple regression models, adjusting for appropriate confounders. Additionally, because we have multiple VOC's, which are highly correlated, we will use methods such as LASSO to identify the VOC's that are most associated with the outcomes of interest. Multipollutant approaches, such as principal component analysis, will be used to test whether overall VOC exposure is associated with the health outcomes. Interaction variables will be tested for in the regression models and subgroup analyses will be conducted according to the following factors: significant interactions, sex, age, race, tobacco product group. Multiple imputation method will be used for missing data where appropriate. Sensitivity analysis using different analytical approaches, such as generalised linear models, as well as considering different covariate adjustments, will be used to build concordant results.

The dose dependence of the changes in biomarkers will be determined by analysing the data obtained from individuals that are exposed to different doses of a single product (eg, smoking $0,<10,10-20$ and $>20$ cigarettes per day) and by comparing between tobacco products that have different doses of HPHC constituents. In the USA, the average cigarettes per day is between 10 and $20^{44}$ and therefore this dose range distribution is reflective of general population exposure. Comparisons of the effects of novel tobacco products and smoking will be informative of the relative toxicity of the two products.

We believe that the methods employed in the current project are exquisitely sensitive and responsive to even low-dose insults such as ambient air pollution ${ }^{12}$ allowing us to quantify tobacco product-induced changes with high precision. Moreover, levels of acrolein exposure vary between different individuals due to difference in puffing intensity and the time a cigarette is left smouldering. Thus, direct measurements of acrolein metabolites afford better estimates of acrolein exposure than machine yields. We expect to obtain wide variations in acrolein/crotonaldehyde exposure which will enable us to construct a dose-response relationship and identify which injury biomarkers are associated with aldehyde exposure and whether high levels of exposure are associated with high levels of injury, despite similar nicotine delivery.

\section{ETHICS AND DISSEMINATION}

All participants provide written consent. No study-related procedures will be completed until after participant consent.

Participants for the CITU study are being recruited in both Boston, Massachusetts, and Louisville, Kentucky. The two populations show significant differences, therefore, recruitment at two sites will ensure a range more reflective of the general population. Although overall racial and ethnic demographics for both cities show a clear majority of Caucasians $(70 \%)$ and despite smokers typically male, we strive to, and currently are successful in, recruiting a population that was gender balanced and almost evenly split between Caucasian and African-Americans. Despite this balanced recruitment, e-cigarette users have been reported as predominantly Caucasian and male,${ }^{45}$ and thus far our recruitment mirrors these demographics. We expect very few Hispanic/Latino's to participate, due to data suggesting tobacco use, including ENDs, tends to be lower among Hispanic's/ Latino's. ${ }^{46}$ Thus, we have also opted to only recruit English speakers. We have carefully developed our recruitment strategy and exclusion criteria to protect vulnerable populations, which is important since many report a lower socioeconomic status and educational level in smokers in addition to higher rates of reported alcohol and drug use. ${ }^{47} 48$

Our study is an observational study where participants have already assumed the risk of using tobacco. Study procedures pose minimal risk. Given the known harms associated with smoking, we will provide information on tobacco treatment when requested by the participant. Participant information is de-identified for analysis and reported in aggregate to protect privacy. 
Completion of these studies will enable a greater understanding of the biological responses to use of a variety of tobacco products. Specifically, they will help to identify the constituents of these products; and how a panel of exposure and CV injury biomarkers are associated with these different constituents. This data will be available to the Food and Drug Administration and could help guide new policy measures to reduce or eliminate the harmful components of tobacco smoke and other nicotine products. The study is dedicated to the rapid dissemination of their rigorously characterised and well-controlled research findings to the public in the form of peer-reviewed publications. Subsequent to the initial full-length manuscript publications of the resources generated with funding from this programme, the study will make them available to interested and qualified investigators on written request. The study will provide relevant protocols of published data, on request (presuming prior publication by the centre members). Participants will be provided a summary of the results as they become available. Finally, press releases of relevant findings will inform the general population.

Contributors RJK: study design, study recruitment, study visits, statistical analysis and manuscript preparation. JLF: study recruitment, study visits, manuscript preparation and editing. DWR: statistical analysis, manuscript preparation and editing. TO: biomarker measurements, manuscript preparation and editing. JLN: study recruitment and study visits. MH: study recruitment and study visits. PL: volatileorganic compound measurements and manuscript preparation. AB: study design, study funding and manuscript editing. APD: human subject assessment planning, manuscript preparation and editing. NMH: study design, study funding, vascular core, manuscript preparation and editing.

Funding This work was supported by the National Institutes of Health and the FDA Center for Tobacco Products (CTP) grant number P50HL120163.

Disclaimer The content is solely the responsibility of the authors and does not necessarily represent the official views of the NIH or the Food and Drug Administration.

Competing interests None declared.

Patient consent Not required.

Ethics approval The CITU study was approved at each institution by their institutional review board (BU \#H-32613 and UofL \#13.0590).

Provenance and peer review Not commissioned; externally peer reviewed.

Open Access This is an Open Access article distributed in accordance with the Creative Commons Attribution Non Commercial (CC BY-NC 4.0) license, which permits others to distribute, remix, adapt, build upon this work non-commercially, and license their derivative works on different terms, provided the original work is properly cited and the use is non-commercial. See: http://creativecommons.org/ licenses/by-nc/4.0/

(C) Article author(s) (or their employer(s) unless otherwise stated in the text of the article) 2018. All rights reserved. No commercial use is permitted unless otherwise expressly granted.

\section{REFERENCES}

1. Rostron B. Smoking-attributable mortality by cause in the United States: revising the CDC's data and estimates. Nicotine Tob Res 2013;15:238-46.

2. Morris PB, Ference BA, Jahangir E, et al. Cardiovascular effects of exposure to cigarette smoke and electronic cigarettes: clinical perspectives from the prevention of cardiovascular disease section leadership council and early career councils of the American College of Cardiology. J Am Coll Cardiol 2015;66:1378-91.
3. Haussmann $\mathrm{HJ}$. Use of hazard indices for a theoretical evaluation of cigarette smoke composition. Chem Res Toxicol 2012;25:794-810.

4. Ghilarducci DP, Tjeerdema RS. Fate and effects of acrolein. Rev Environ Contam Toxicol 1995;144:95-146.

5. Dong JZ, Moldoveanu SC. Gas chromatography-mass spectrometry of carbonyl compounds in cigarette mainstream smoke after derivatization with 2,4-dinitrophenylhydrazine. J Chromatogr A 2004;1027:25-35.

6. Stepanov I, Jensen J, Hatsukami D, et al. New and traditional smokeless tobacco: comparison of toxicant and carcinogen levels. Nicotine Tob Res 2008;10:1773-82.

7. Awe SO, Adeagbo AS, D'Souza SE, et al. Acrolein induces vasodilatation of rodent mesenteric bed via an EDHF-dependent mechanism. Toxicol Appl Pharmacol 2006;217:266-76.

8. Conklin DJ, Barski OA, Lesgards JF, et al. Acrolein consumption induces systemic dyslipidemia and lipoprotein modification. Toxicol Appl Pharmacol 2010;243:1-12.

9. Conklin DJ, Bhatnagar A, Cowley HR, et al. Acrolein generation stimulates hypercontraction in isolated human blood vessels. Toxicol Appl Pharmacol 2006;217:277-88.

10. Conklin DJ, Haberzettl P, Prough RA, et al. Glutathione-Stransferase $P$ protects against endothelial dysfunction induced by exposure to tobacco smoke. Am J Physiol Heart Circ Physiol 2009;296:H1586-97.

11. Ismahil MA, Hamid T, Haberzettl P, et al. Chronic oral exposure to the aldehyde pollutant acrolein induces dilated cardiomyopathy. $\mathrm{Am} \mathrm{J}$ Physiol Heart Circ Physiol 2011;301:H2050-60.

12. O'Toole TE, Hellmann J, Wheat $\mathrm{L}$, et al. Episodic exposure to fine particulate air pollution decreases circulating levels of endothelial progenitor cells. Circ Res 2010;107:200-3.

13. O'Toole TE, Zheng YT, Hellmann J, et al. Acrolein activates matrix metalloproteinases by increasing reactive oxygen species in macrophages. Toxicol Appl Pharmacol 2009;236:194-201.

14. Sithu SD, Srivastava S, Siddiqui MA, et al. Exposure to acrolein by inhalation causes platelet activation. Toxicol Appl Pharmacol 2010;248:100-10.

15. Srivastava S, Sithu SD, Vladykovskaya E, et al. Oral exposure to acrolein exacerbates atherosclerosis in apoE-null mice. Atherosclerosis 2011;215:301-8.

16. Tsakadze NL, Srivastava S, Awe SO, et al. Acrolein-induced vasomotor responses of rat aorta. Am J Physiol Heart Circ Physiol 2003;285:H727-34.

17. Wang GW, Guo Y, Vondriska TM, et al. Acrolein consumption exacerbates myocardial ischemic injury and blocks nitric oxideinduced PKCepsilon signaling and cardioprotection. J Mol Cell Cardiol 2008;44:1016-22.

18. Wheat LA, Haberzettl P, Hellmann J, et al. Acrolein inhalation prevents vascular endothelial growth factor-induced mobilization of Flk-1+/Sca-1+ cells in mice. Arterioscler Thromb Vasc Biol 2011;31:1598-606.

19. WHO study group on tobacco product regulation. Report on the scientific basic of tobacco product regulation: fourth report of a WHO study group. World Health Organ Tech Rep Ser 2012:1-83.

20. De Woskin R, Greenberg M, Pepelko W, et al. Toxicological review of acrolein (cas no. 107-02-08) in support of summary information on the integrated risk information system (Iris). Washington, DC: US Environmental Protection Agency, 2003.

21. Kosmider L, Sobczak A, Fik M, et al. Carbonyl compounds in electronic cigarette vapors: effects of nicotine solvent and battery output voltage. Nicotine Tob Res 2014;16:1319-26.

22. Goniewicz ML, Knysak J, Gawron M, et al. Levels of selected carcinogens and toxicants in vapour from electronic cigarettes. Tob Control 2014;23:133-9.

23. Wang P, Chen W, Liao J, et al. A device-independent evaluation of carbonyl emissions from heated electronic cigarette solvents. PLOS One 2017:12:e0169811.

24. Hill JM, Zalos G, Halcox JP, et al. Circulating endothelial progenitor cells, vascular function, and cardiovascular risk. N Engl J Med 2003;348:593-600

25. Parsons VL, Moriarity C, Jonas $\mathrm{K}$, et al. Design and estimation for the national health interview survey, 2006-2015. Vital Health Stat 2 2014:1-53

26. Raysoni AU, Stock TH, Sarnat JA, et al. Evaluation of VOC concentrations in indoor and outdoor microenvironments at nearroad schools. Environ Pollut 2017;231(Pt 1):681-93.

27. Boyle EB, Viet SM, Wright DJ, et al. Assessment of exposure to VOCs among Pregnant Women in the National Children's Study. Int $J$ Environ Res Public Health 2016;13:376.

28. Jain RB. Distributions of selected urinary metabolites of volatile organic compounds by age, gender, race/ethnicity, and smoking status in a representative sample of U.S. adults. Environ Toxicol Pharmacol 2015;40:471-9. 
29. Sarkar M, Muhammad-Kah R, Liang Q, et al. Evaluation of spot urine as an alternative to $24 \mathrm{~h}$ urine collection for determination of biomarkers of exposure to cigarette smoke in adult smokers. Environ Toxicol Pharmacol 2013;36:108-14.

30. Benowitz NL, Jacob P. Nicotine and cotinine elimination pharmacokinetics in smokers and nonsmokers. Clin Pharmacol Ther 1993:53:316-23.

31. Fuhr U, Boettcher MI, Kinzig-Schippers M, et al. Toxicokinetics of acrylamide in humans after ingestion of a defined dose in a test meal to improve risk assessment for acrylamide carcinogenicity. Cancer Epidemiol Biomarkers Prev 2006;15:266-71.

32. DeJarnett N, Conklin DJ, Riggs DW, et al. Acrolein exposure is associated with increased cardiovascular disease risk. J Am Heart Assoc 2014;3:e000934.

33. Alwis KU, Blount BC, Britt AS, et al. Simultaneous analysis of 28 urinary VOC metabolites using ultra high performance liquid chromatography coupled with electrospray ionization tandem mass spectrometry (UPLC-ESI/MSMS). Anal Chim Acta 2012;750:152-60.

34. Vasa M, Fichtlscherer S, Aicher A, et al. Number and migratory activity of circulating endothelial progenitor cells inversely correlate with risk factors for coronary artery disease. Circ Res 2001;89:e1-7.

35. Werner N, Nickenig G. Influence of cardiovascular risk factors on endothelial progenitor cells: limitations for therapy? Arterioscler Thromb Vasc Biol 2006;26:257-66.

36. DeJarnett N, Yeager R, Conklin DJ, et al. Residential proximity to major roadways is associated with increased levels of AC133 circulating angiogenic cells. Arterioscler Thromb Vasc Biol 2015;35:2468-77.

37. Poredos P, Orehek M, Tratnik E. Smoking is associated with dose-related increase of intima-media thickness and endothelial dysfunction. Angiology 1999;50:201-8.
38. Heiss C, Amabile N, Lee AC, et al. Brief secondhand smoke exposure depresses endothelial progenitor cells activity and endothelial function: sustained vascular injury and blunted nitric oxide production. J Am Coll Cardiol 2008:51:1760-71.

39. Flammer AJ, Anderson T, Celermajer DS, et al. The assessment of endothelial function: from research into clinical practice. Circulation 2012;126:753-67.

40. Benjamin EJ, Larson MG, Keyes MJ, et al. Clinical correlates and heritability of flow-mediated dilation in the community: the Framingham Heart Study. Circulation 2004;109:613-9.

41. Vita JA. Nitric oxide-dependent vasodilation in human subjects. Methods Enzymol 2002;359:186-200.

42. Mitchell GF, Guo CY, Benjamin EJ, et al. Cross-sectional correlates of increased aortic stiffness in the community: the Framingham Heart Study. Circulation 2007:115:2628-36.

43. Duffy SJ, Keaney JF, Holbrook M, et al. Short- and long-term black tea consumption reverses endothelial dysfunction in patients with coronary artery disease. Circulation 2001;104:151-6.

44. Benowitz NL, Dains KM, Dempsey D, et al. Racial differences in the relationship between number of cigarettes smoked and nicotine and carcinogen exposure. Nicotine Tob Res 2011;13:772-83.

45. Schoenborn CA, Gindi RM. Electronic cigarette use among adults: United States, 2014. NCHS Data Brief 2015:1-8.

46. Maher JE, Boysun MJ, Rohde K, et al. Are latinos really less likely to be smokers? Lessons from Oregon. Nicotine Tob Res 2005;7:283-7.

47. Barbeau EM, Krieger N, Soobader MJ. Working class matters: socioeconomic disadvantage, race/ethnicity, gender, and smoking in NHIS 2000. Am J Public Health 2004;94:269-78.

48. Giskes K, Kunst AE, Benach J, et al. Trends in smoking behaviour between 1985 and 2000 in nine European countries by education. $J$ Epidemiol Community Health 2005;59:395-401. 